\title{
Influence of omega-6 PUFA arachidonic acid and bone marrow adipocytes on metastatic spread from prostate cancer
}

\author{
MD Brown ${ }^{*, 1}$, C Hart', E Gazi', P Gardner², N Lockyer² and N Clarke ${ }^{1,3,4}$ \\ 'Genito-Urinary Cancer Research Group, School of Cancer, Enabling Sciences and Technology, Paterson Institute for Cancer Research, The University of \\ Manchester, Manchester Academic Health Science Centre, The Christie NHS Foundation Trust, Manchester M20 4BX, UK; ${ }^{2}$ School of Chemical \\ Engineering and Analytical Sciences, Manchester Interdisciplinary Biocentre (MIB), The University of Manchester, I 3 I Princess Street, Manchester M I \\ 7DN, UK; ${ }^{3}$ Department of Urology, The Christie NHS Foundation Trust, Wilmslow Road, Manchester M20 4BX, UK; ${ }^{4}$ Department of Urology, Salford \\ Royal Hope NHS Foundation Trust, Stott Lane, Salford M6 8HD, UK
}

BACKGROUND: Prostate cancer (CaP) preferentially metastasises to the bone, and we have previously shown that the poly-unsaturated fatty acid (PUFA) arachidonic acid (AA) is a potent stimulator of CaP invasion. Here we present that AA promotes CaP invasion by inducing bone marrow adipocyte formation.

METHODS: Boyden invasion-chamber assays assessed the ability of dietary oils, their PUFA components, and specific PUFA-loaded adipocytes to induce PC-3 invasion. Lipid transfer and metabolism was followed using deuterated AA and Fourier Transform Infrared spectroscopy (FTIR).

RESULTS: Poly-unsaturated fatty acid constituents, but not their corresponding dietary oils, induced PC-3 invasion. PUFAs induce bone marrow adipocyte (BM-Ad) differentiation with AA inducing higher levels of BM-Ad differentiation, as compared with other PUFAs (3998 \pm 514.4 vs 932 $\pm 265.8 ; P=0.00002)$, which stimulated greater $P C-3$ invasion than free AA (22408.5 \pm 607.4 vs $16236 \pm 313.9 ; P=0.01 \mathrm{III}$ ) or adipocytes generated in the presence of other PUFAs. In bone marrow co-culture PC-3 and BM-Ad interactions result in direct uptake and metabolism of AA by PC-3 cells, destruction of the adipocyte and subsequent formation of a bone metastasis.

CONCLUSION: The data supports the hypothesis that AA not only promotes CaP invasion, it also prepares the 'soil', making it more supportive for implantation and propagation of the migrating metastatic cell.

British Journal of Cancer (2010) 1 02, 403-4I3. doi:I0.1038/sj.bjc.660548I www.bjcancer.com

Published online 8 December 2009

(c) 2010 Cancer Research UK

Keywords: arachidonic acid; bone marrow; prostate cancer; lipid; metastasis; adipocytes

A high proportion of young men have microscopic evidence of prostate cancer $(\mathrm{CaP})$ with prevalence increasing with age (Franks, 1954). Notwithstanding the global similarity in prevalence, the incidence of clinical $\mathrm{CaP} / \mathrm{CaP}$ death varies widely internationally. In western societies, clinical $\mathrm{CaP}$ is common compared with developed non-western countries, for example Japan (Ferlay et al, 2004). Migrational studies also show that movement from low- to high-risk countries raises $\mathrm{CaP}$ risk in migrants to that in native residents, (Crawford, 2003) suggesting that environmental factors affect CaP's clinical incidence and mortality.

Epidemiological studies highlight differences in the omega- 6 $(\omega-6)$ to omega-3 ( $\omega-3)$ polyunsaturated fatty acid (PUFA) ratio between regions of high and low $\mathrm{CaP}$ risk. PUFA makes up $19-22 \%$ of fat energy intake in the United States of America, with $84-89 \%$ coming from the $\omega-6$ linoleic acid (LA). The $\omega-3 \alpha-$ linolenic acid (ALA) only contributes $9-11 \%$ of PUFA-related energy (Kris-Etherton et al, 2000), giving an $\omega-6: \omega-3$ ratio of $10.6: 1$. This compares with $4: 1$ in Japan and is well above the perceived optimal ratio of $2.3: 1$ (Sugano and Hirahara, 2000). It is interesting to note that the increases in incidence and mortality

*Correspondence: Dr MD Brown, E-mail: mbrown@picr.man.ac.uk Received 2 July 2009; revised 3 November 2009; accepted II November 2009; published online 8 December 2009 from $\mathrm{CaP}$ in developing countries over the last 30 years has coincidentally mirrored the increased dietary $\omega-6: \omega-3$ PUFA ratio brought about by greater vegetable oil consumption and the use of cereal grain to feed livestock.

Diets enriched with high levels of $\omega-6$ PUFAs, particularly LA and its metabolite arachidonic acid (AA), are associated with poorer CaP prognosis (Wynder et al, 1994; Rose, 1997). The precise mechanism of this is unclear. Arachidonic acid exerts influence through its COX-2 and LOX metabolites, inducing malignant CaP proliferation (Hughes-Fulford et al, 2006), inhibiting apoptosis (Ghosh, 2004), inducing angiogenesis (Nie et al, 1998), and inducing disease progression (Honn et al, 1994; Norrish et al, 1999). Studies of the 5-LOX product, 5-HETE, show this is as a key regulator of tumour aggressiveness. 5-HETE protects prostate cells from apoptosis (Ghosh, 2004) and is crucial in EGF-related cellular proliferation (Hassan and Carraway, 2006). Arachidonic acid itself is a potent stimulator of malignant prostate epithelial cell (PEC) invasion, and is able to recover invasion towards adipocyte-free human bone marrow stroma (BMS) by the AA metabolite $\mathrm{PGE}_{2}$. This stimulatory effect is abrogated by the addition of long chain marine $\omega$-3 PUFAs eicosapentaenoic acid (EPA) and docosahexaenoic acid (DHA) (Brown et al, 2006). It has also been hypothesised that AA acts as a secondary messenger involving an autocrine loop-maintaining EGFR activation (Angelucci et al, 2008). 
Prostate cancer metastasises preferentially to the BMS. The reasons underlying this are uncertain but evidence suggests that $\mathrm{BM}$ adipocytes (BM-Ad) are of importance. The precise role of BM-Ad, present in abundance in BMS, is unknown. It is hypothesised that they have a role in haematopoiesis (Gimble et al, 1992) or act as energy stores supporting oxidative metabolism of resorbing osteoclasts (Dodds et al, 1994) and are fundamental to BMS formation and its long-term maintenance (Gartner and Kaplan, 1980). In long-term human BMS/CaP models malignant cells migrate towards BM-Ad and take up lipids from adipocytes or the surrounding microenvironment (Brown et al, 2006). Separate studies by Tokuda et al (2003) and Gazi et al (2007) found that PC-3 cells interacted directly with adipocytes and using Fourier Transform Infrared spectroscopy (FTIR) to follow deuterated palmitic acid, Gazi et al (2007) confirmed the direct uptake of lipid by $\mathrm{CaP}$ cells from BM-Ad.

Polyunsaturated fatty acids acting in vitro are potent inducers of adipocyte differentiation (Madsen et al, 2005), but the roles of dietary PUFAs and their effect on $\mathrm{BM}$ adipogenesis and $\mathrm{CaP}$ metastasis are unknown. Here we show that dietary PUFAs themselves are not strong stimulators of $\mathrm{CaP}$ invasion but require adipocyte processing. We also show that AA induces invasion itself and induces differentiation of BM mesenchymal stem cells (MSC) into adipocytes, which are themselves potent inducers of invasion. Together the data suggests that a high level of AA derived from dietary intake is a major risk factor for $\mathrm{CaP}$ progression.

\section{MATERIALS AND METHODS}

\section{Materials}

All general reagents were purchased from Sigma-Aldrich (Poole, $\mathrm{UK}$ ), including all the lipids except AA (MP Biomedicals, London, UK). All lipids except $D_{8}$-AA were either made up in ethanol or methyl- $\beta$-cyclodextrin to produce a $10 \mathrm{mg} \mathrm{ml}^{-1}$ emulsion. $\mathrm{D}_{8}$-AA was supplied in methyl acetate, which was removed by evaporation under a nitrogen gas stream at room temperature before dissolving in ethanol. All tissue culture reagents were from Invitrogen (Paisley, UK) except Hygromycin B, which was obtained from PAA Laboratories (Yeovil, UK). Foetal calf serum (FCS) was supplied by Labtech International (Uckfield, East Sussex, UK). Matrigel basement membrane matrix and $8 \mu \mathrm{m}$ FluoroBlok cell culture inserts were from BD Biosciences (Oxford, UK). RosetteSep MSC enrichment cocktail and MesenCult basal media were supplied by StemCell Technologies (London, UK).

\section{Cell lines and primary BMS culture}

PC-3 (ATCC, Manassas, VA, USA) and the PC3-GFP cell lines were cultured in Ham's F12, 7\% FCS and $2 \mathrm{~mm}$ L-glutamine, with the addition of Hygromycin B $\left(0.15 \mathrm{mg} \mathrm{ml}^{-1}\right)$ for the GFP variant, at $37^{\circ} \mathrm{C}$, $5 \% \mathrm{CO}_{2}$ in air. BMS was cultured from human ribs removed for access during routine renal surgery for non-malignant disease after informed consent. BMS cultures were prepared according to the method of Coutinho et al (1993) and cultured in long-term culture medium (Iscove's Modified Dulbecco's Medium containing 10\% FCS, 10\% horse serum and $50 \mu \mathrm{M}$ hydrocortisone) or used for MSC isolation.

\section{Mesenchymal separation from normal rib}

Mesenchymal stem cells were isolated from human donor red cellenriched rib bone marrow using the RosetteSep human MSC enrichment cocktail and cultured as defined by Gazi et al (2007). Briefly, human donor red cell-enriched rib bone marrow was incubated with RosetteSep antibody cocktail $\left(50 \mu \mathrm{g} \mathrm{ml}^{-1}\right)$ for $20 \mathrm{~min}$ at room temperature. Cells were diluted with two volumes of PBS $+2 \%$ FCS, $1 \mathrm{~mm}$ EDTA before centrifuging at $300 \mathrm{~g}$ for $25 \mathrm{~min}$ at room temperature over a Ficoll-Paque cushion. Enriched cells were plated at $1 \times 10^{7}$ cells $25 \mathrm{~cm}^{-2}$ flask in complete media (90 ml MSC basal medium/10 ml MSC stimulatory supplement) and incubated at $37^{\circ} \mathrm{C}, 5 \% \mathrm{CO}_{2}$ in air. After $24 \mathrm{~h}$, non-adherent cells were removed and fresh complete media added. Media was refreshed every 3-4 days until confluent. Adipogenesis was induced by replacing the basal media with proprietary MSC adipogenic media or with MSC basal medium containing $50 \mu \mathrm{M}$ hydrocortisone and $50 \mu \mathrm{m}$ lipid. Cultures were incubated at $37^{\circ} \mathrm{C}$, $5 \% \mathrm{CO}_{2}$ in air and media was refreshed every 14 days until adipocytes were present.

\section{Invasion assay}

A variation of the invasion co-cultures described by Hart et al (2005) was used. Briefly, FluoroBlok cell culture inserts $(8 \mu \mathrm{m})$ coated with Matrigel diluted 1:25 with phenol red free RPMI 1640 medium, were placed in a 24-well plate containing $1 \mathrm{ml}$ of RPMI 1640 (w/o phenol red)/0.1\% fatty acid free (FAF) BSA/ $10 \mathrm{mM}$ HEPES with either tissue culture plastic (TCP), BMS, mBMAd or lipids in the base. PC-3 GFP cells $\left(2 \times 10^{5}\right.$ cells in $0.25 \mathrm{ml}$ of RPMI $1640 / 0.1 \%$ FAF BSA) were seeded on top of the inserts. Following incubation at $37^{\circ} \mathrm{C}$ for $24 \mathrm{~h}$ invasion was assessed on a BMG FLUOstar OPTIMA plate reader at $488 / 520 \mathrm{~nm}$ (excitation/emission filter). The number of adipocytes in each well was scored post fixation with $4 \%$ Formalin for $20 \mathrm{~min}$ at room temperature.

\section{Cell fixation}

$\mathrm{D}_{8}$-arachidonic acid labelled adipocytes on MirrIR plates were washed twice with PBS and seeded with $1 \times 10^{5} 24 \mathrm{~h}$ serum-starved PC-3 cells. After $48 \mathrm{~h}$ of incubation in serum-free RPMI at $37^{\circ} \mathrm{C}$, $5 \% \mathrm{CO}_{2}$ in air cultures were washed twice with PBS and fixed in $4 \%$ paraformaldehyde for $25 \mathrm{~min}$. Cells were washed thrice for $5 \mathrm{~min}$ each in Sorensen's buffer $(0.15 \mathrm{M}, \mathrm{pH} 7.4)$ and post-fixed in $1 \%$ $\mathrm{OsO}_{4}$ for $1 \mathrm{~h}$. Cells were washed thrice for $5 \mathrm{~min}$ each with Sorensen's buffer before dehydration using increasing concentrations of ethanol: water. Cells were then dried using a critical point drier. The ethanol was substituted for liquid $\mathrm{CO}_{2}$ following six ethanol- $\mathrm{CO}_{2}$ exchanges and a $5 \mathrm{~min}$ immersion (repeated nine times). Phase-transition was induced by heating the chamber to $\sim 45^{\circ} \mathrm{C}$ at 1200 psi. Preservation was assessed by microscopy. The cells were stored in a desiccator until FTIR analysis.

\section{FTIR micro-spectroscopy}

High-definition FTIR micro-spectroscopic maps of paraformaldehyde-OsO ${ }_{4}-\mathrm{CPD}$ fixed adipocyte-PC-3 cell co-cultures were collected in rapid-scan reflectance mode at $6.25 \mu \mathrm{m}$ pixel resolution using a Perkin Elmer Spotlight spectrometer with a $16 \times 1$ MCT linear-array detector. The background scan was recorded at 8 or $4 \mathrm{~cm}^{-1}$ spectral resolution with 75 scans, whereas the sample scan was recorded at 8 or $4 \mathrm{~cm}^{-1}$ spectral resolution with 64 scans.

\section{Time-lapse microspectroscopy}

Confluent adipogenically active human BMS in T12.5 flasks were seeded with serum starved PC-3 cells and observed using a time-lapse video microscope capturing one frame every $20 \mathrm{~s}$ (Allen, 1987).

\section{Statistics}

All values are presented as mean \pm s.e.m. All assays were compared with use of the two-tailed Student's $t$-test. A threshold of significance was set at $P<0.05$. 


\section{RESULTS}

\section{Dietary oils do not induce invasion, but their PUFA components do}

In order to determine the ability of common dietary oils used in western diets, which contain different levels of $\omega-3 / 6 / 9$ lipids, along with pure individual PUFAs to stimulate $\mathrm{CaP}$ migration we encapsulated the lipids in methyl- $\beta$-cyclodextrin to create an emulsion suitable for cell culture.

Bone marrow stroma control and AA, previously shown to induce maximum PC-3 invasion (Brown et al, 2006), induced significant invasion through Matrigel (Figure 1A). Common dietary oils failed to induce significant invasion compared with controls. Analysis of specific PUFAs in isolation showed induction of PC-3 invasion. Figure 1B-D shows increased invasion induced by increasing concentrations of LA, ALA and oleic acid. The AA precursor LA at a maximum concentration of $30 \mu \mathrm{g} \mathrm{ml}^{-1}$ induced invasion to a level approaching $3 \mu \mathrm{g} \mathrm{ml}^{-1}(10 \mu \mathrm{M})$ AA $(9925.7 \pm 1253.1$ vs $12347.2 \pm 455 ; P=0.09935)$. Both ALA $(\omega-3)$ and oleic acid $(\omega-9)$ induced PC-3 invasion (8406 \pm 1202.9 vs $5054 \pm 334.7 ; P=0.02291$ : LA and TCP control, respectively), but at a significantly lower rate than that from $3 \mu \mathrm{g} \mathrm{ml}^{-1} \mathrm{AA}$ $(P=0.01195)$. The invasive stimulus closest to AA came from $30 \mu \mathrm{g} \mathrm{ml}^{-1}$ oleic acid, which induced equivalent levels to AA (12 192.8 \pm 790.6 vs $12347.2 \pm 455 ; P=0.00001)$.

\section{PUFAs stimulate adipocyte differentiation in BMS}

Prostate cancer cells were not stimulated to invade by complex lipid mixtures in common dietary oils (Figure 1), but were stimulated when PUFAs were presented on their own. Lipids are processed and stored within adipocytes and $\mathrm{CaP}$ preferentially metastasise to the adipocyte-rich red BM. Therefore, we sought to determine the effect of PUFAs on adipocyte formation in BM and on the adipocytes ability to induce CaP invasion.

Bone marrow MSCs isolated from human ribs were differentiated down the adipocyte lineage (mBM-Ad) by culture in mesenchymal stem cell basal media containing hydrocortisone and specific PUFAs. Control MSCs were cultured in proprietary adipogenic media (StemCell Technologies), containing an undisclosed lipid mixture and long-term BMS culture from the same patient. All PUFAs, except AA, induced generation of similar adipocyte numbers within each culture compared with commercial adipogenic media and hydrocortisone 'lipid free' negative control. Arachidonic acid however, induced markedly greater numbers of adipocytes than adipogenic media (3998 \pm 514.4 vs $932.3 \pm 265.8$, respectively; $P=0.00002$ ) (Figure 2 ).

\section{PUFA-loaded adipocytes, especially AA, induce invasion}

The ability of specific lipid pulsed mBM-Ad to stimulate $\mathrm{CaP}$ invasion through Matrigel was compared with invasive stimulation

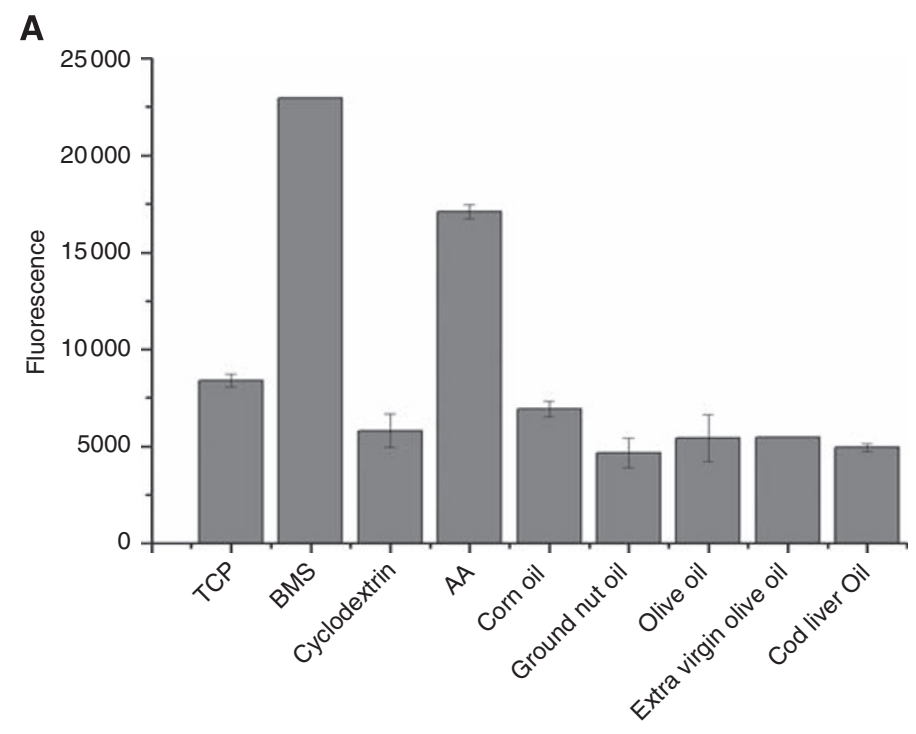

$$
\text { B }
$$
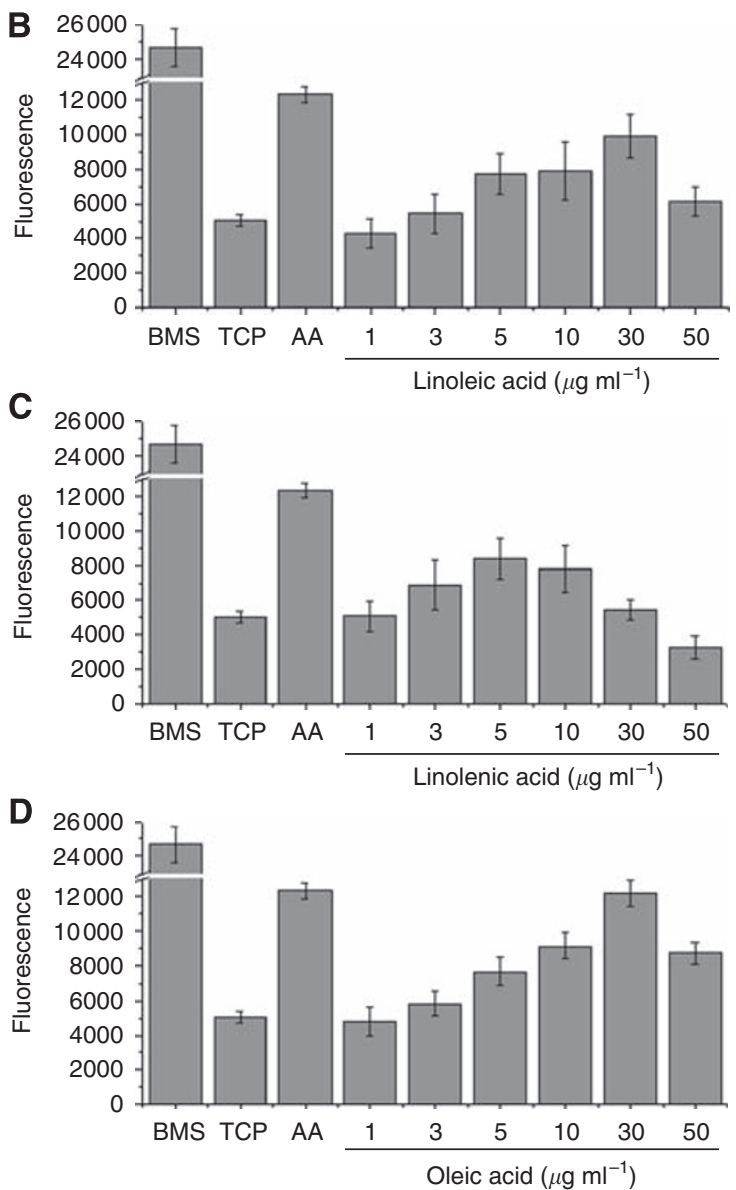

Figure I Poly-unsaturated fatty acid (PUFA) components, but not heterogeneous dietary oils, are stimulators of prostate cancer (CaP) invasion. $2 \times 10^{5}$ PC-3-GFP cells were seeded in modified Boyden chambers above either (A) $|\mu \mathrm{gml}|^{-1}$ dietary lipids or increasing levels of (B) linoleic acid (LA) (C) $\alpha$-linolenic acid (ALA) (D) oleic acid encaged in methyl- $\beta$-cyclodextrin. Levels of invasion are proportional to fluorescence detected by a bottom reading BMG FLUOstar OPTIMA plate reader at $488 / 520 \mathrm{~nm}$ (excitation/emission filter). In each assay $(n=3)$ a serum free RPMI I640 (TCP) ${ }^{-v e}$ control, human $\mathrm{BMS}^{+\mathrm{ve}}$ control and a $3 \mu \mathrm{g} \mathrm{ml}^{-1}$ arachidonic acid (AA) control were included. 
A Bone marrow stroma control

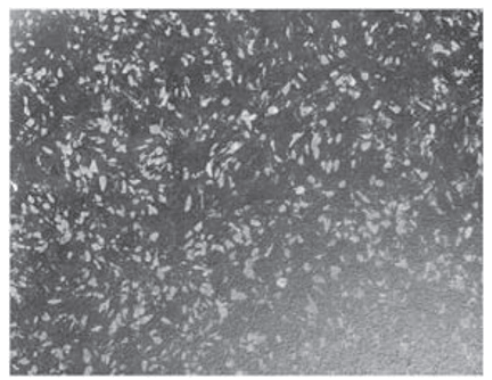

Linoleic acid

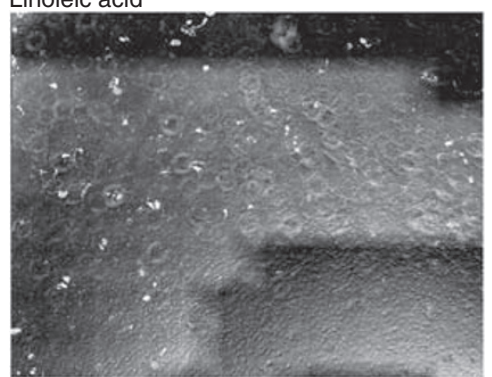

$\alpha$-Linolenic acid

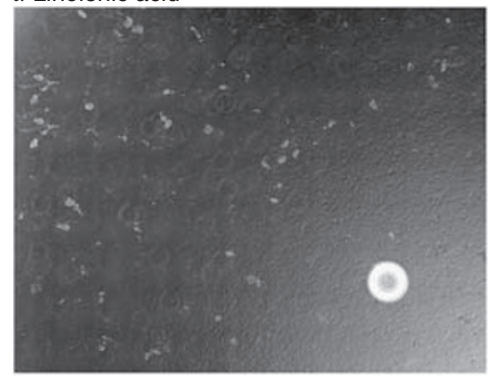

Oleic acid

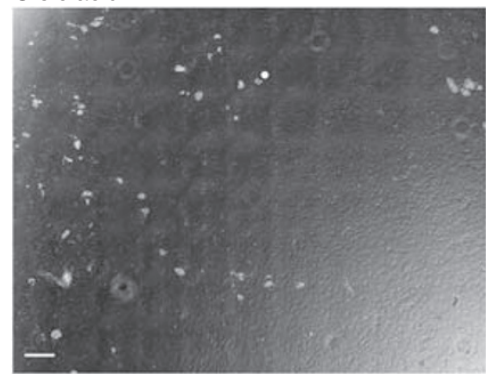

\section{C}

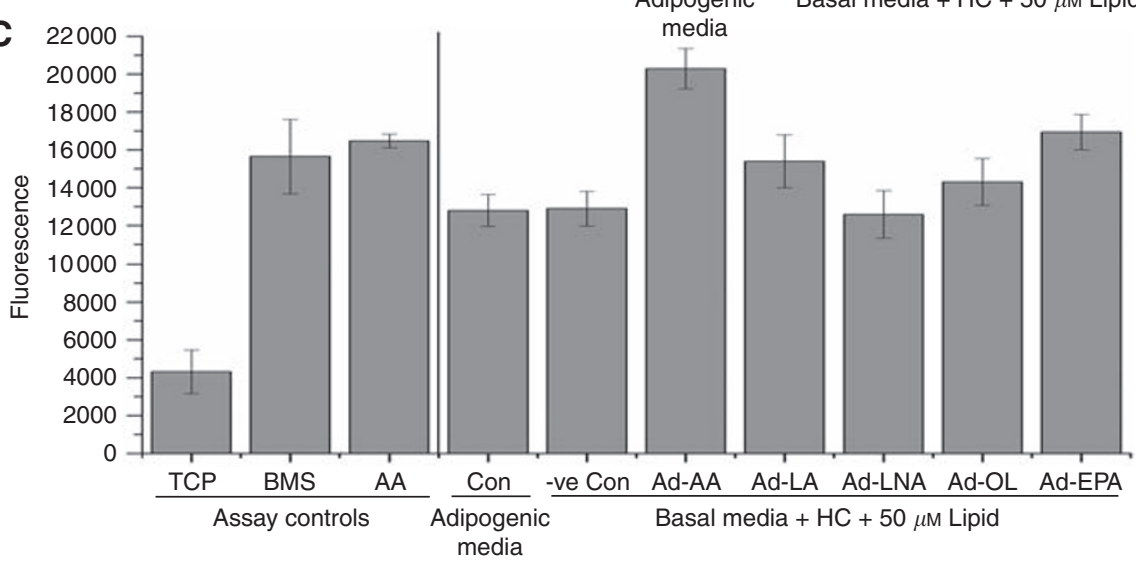

Adipogenic media

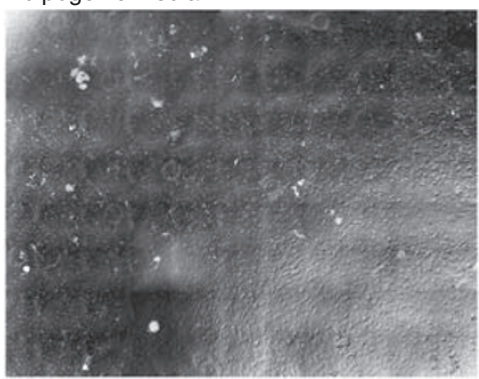

Arachidonic acid
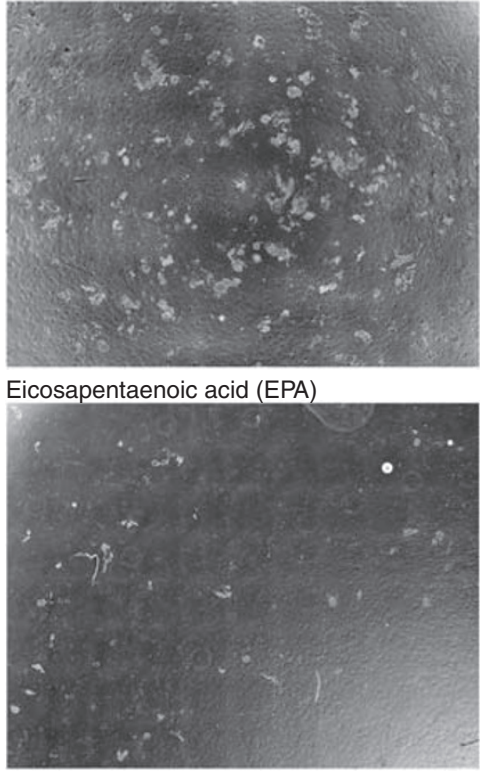

B

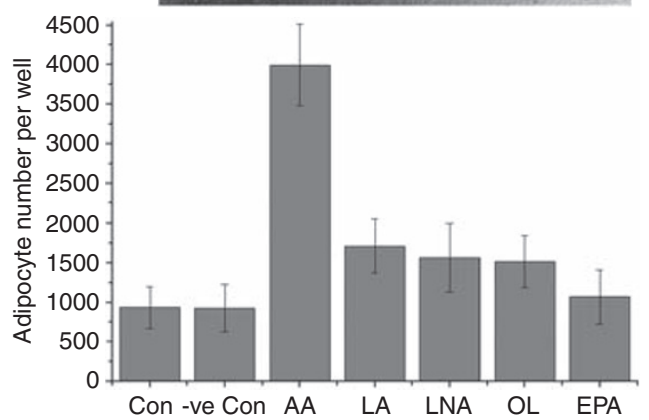

Con -ve Con AA LA LNA OL EPA Adipogenic Basal media $+\mathrm{HC}+50 \mu \mathrm{m}$ Lipid
Eicosapentaenoic acid (EPA) 
by BMS grown under standard conditions and mBM-Ad derived using adipogenic media (Figure 2C). Adipocytes generated by adipogenic media stimulated PC-3 invasion although this was significantly less than that induced by $3 \mu \mathrm{g} \mathrm{ml}^{-1} \mathrm{AA}(11469 \pm 1151.53 \mathrm{vs}$ $16236 \pm 313.9$, respectively; $P=0.00409$ ). It is interesting to note that the level of invasion induced by the adipogenic media was similar to that induced by mesenchymal cells differentiated by hydrocortisone without exogenous lipids (11 165.8 $\pm 871 \quad v s$ $11469 \pm 1151.53 ; P=0.93959)$. This phenomenon was observed with adipocytes differentiated in the presence of ALA, which stimulated PC-3 invasion at similar levels to controls (12429.25 \pm 1002.847 vs $11165.8 \pm 871 \quad(P=0.89279)$ and $1469 \pm 1151.53$ $(P=0.65767)$ for adipogenic media and no lipid control, respectively) and was significantly different to the free AA positive control $(P=0.0241)$.

Adipocytes loaded with $\omega-6$ LA or with $\omega-9$ oleic acid both induced invasion at similar levels to $3 \mu \mathrm{g} \mathrm{ml}^{-1}$ free AA (16459 \pm 1261.6 and $14596 \pm 696.19$ vs $16236 \pm 313.9 ; P=0.52990$ and $P=0.16877)$. Invasion was greater than that induced by adipogenic media and the 'no lipid' controls, but the increase did not reach significance $(11469 \pm 1151.5 P=0.13418$ and $0.05861,11165.8 \pm 871 P=0.33484$ and 0.14815 respectively). Surprisingly, EPA-dosed adipocytes stimulated a significantly greater invasive stimulus than either negative control $(P=0.00543$ and 0.0023$)$ achieving levels similar to $3 \mu \mathrm{g} \mathrm{ml}^{-1}$ free AA $(16927.6 \pm 928.7$ vs $16236 \pm 313.86 P=0.6887)$.

The most striking effect was seen in adipocytes formed in the presence of AA, these generated the greatest invasive stimulus for PC-3 cells compared with negative lipid free control (22 408.5 \pm 607.4 vs $11165.8 \pm 871 P=0.00005)$. The stimulus was greater than that induced by free AA within the media of the bottom chamber $(16236 \pm 313.9 P=0.01111 \mathrm{BM}-\mathrm{Ad}-\mathrm{AA} v s$ free AA, respectively).

\section{CaP cells within BMS migrate to and interact with adipocytes}

mBM-Ad derived from $\mathrm{BM}$ mesenchymal cells grown with AA are potent stimulators of PC-3 invasion. Whether this is because of leeching of PUFAs into the surrounding media from adipocytes, producing higher local concentrations or to undetermined adipocyte-related factors is unclear.

As migrating $\mathrm{CaP}$ cells within the BMS take up lipids (Brown et al, 2006) we utilised mBM-Ad pulsed with $\mathrm{D}_{8}$-AA to determine whether these cancer cells take up lipids released from the mBM-Ad into the BMS environment or whether the process is mediated through direct interaction with the adipocytes themselves. A white light micrograph (Figure 3) shows a mBM-Ad overlaid with the FTIR spectral maps correlating to the vibrational spectral characteristics $v(C-D)$ and $v(=C-D)$ of $\mathrm{D}_{8}$-AA and demonstrates clearly that $\mathrm{D}_{8}$-AA lies within the adipocyte.

Using time-lapse video-microscopy we followed the migration of serum-starved PC-3 cells in co-culture with BMS containing $\mathrm{D}_{8}$-AA-loaded adipocytes (Figure $4 \mathrm{~A}$ and video, Supplementary Figure 3). Binding of the rounded PC-3 cells to BMS was complete within $120 \mathrm{~min}$ following addition of the cells. The PC-3 cells migrated towards adipocytes with first contact observed after approximately $2.5 \mathrm{~h}$. Over the next $2 \mathrm{~h}$ the PC-3 cells appeared to flatten, taking on a mesenchymal morphology. During this period the size of the upper adipocyte in the viewing field decreased in size as it was destroyed, and that the lipid vesicles within adipocytes in the lower aspects of the field began to alter, becoming smaller. The destruction of the upper adipocytes continued over the next $46 \mathrm{~h}$, with adipocytes being disrupted after approximately $12.5 \mathrm{~h}$ and with almost complete loss of the adipocyte/intra-adipocyte lipid vesicles at $48 \mathrm{~h}$. The lower adipocyte was still present at the end of the co-culture, but it had undergone marked changes in its morphology, intra-cellular lipid vesicles, which became smaller in size, along with a reduction in overall cell size. During this process there was a synchronous and obvious visible increase in the number of $\mathrm{CaP}$ cells recruited to adipocytes, with clear morphological change to a mesenchymal phenotype and a marked increase in $\mathrm{CaP}$ cellular motility.
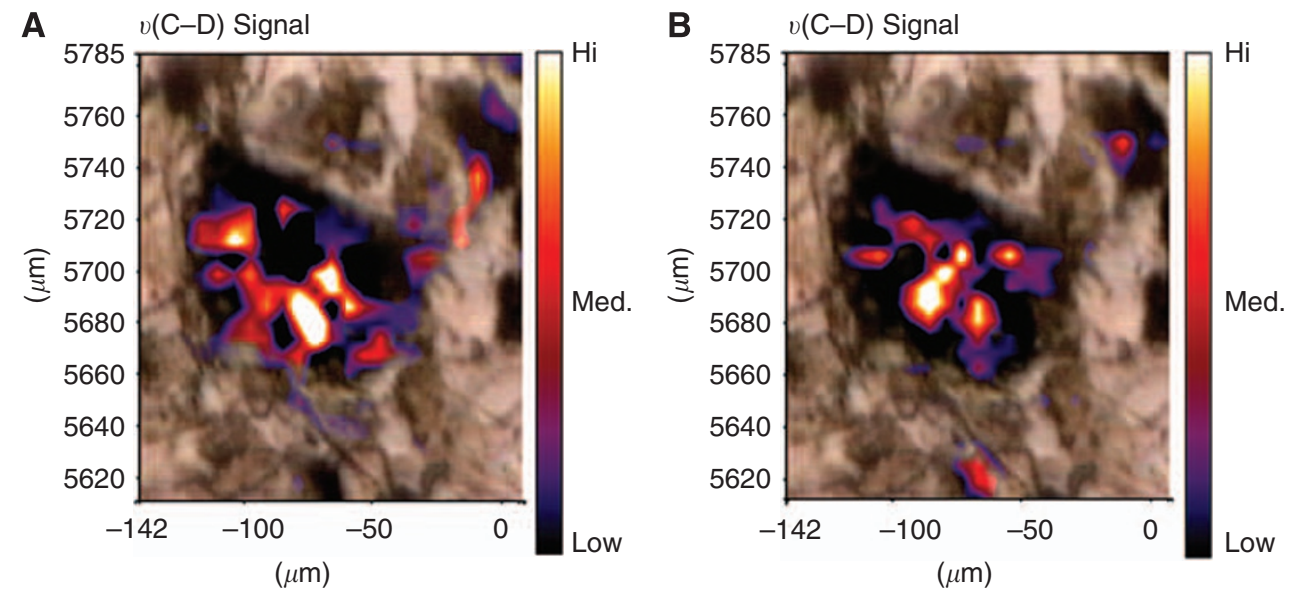

Figure 3 Localisation of $D_{8}$-AA within bone marrow (BM) adipocytes. Deuterated signal overlaid onto phase contrast photomicrograph of a $D_{8}$-AA loaded BM adipocyte. BM mesenchymal stem cells (MSC) were differentiated into adipocytes with $50 \mu \mathrm{M} \mathrm{D}_{8}$-AA. Phase contrast image of an adipocyte overlaid with $(\mathbf{A}) v(\mathrm{C}-\mathrm{D})$ Fourier Transform Infrared spectroscopy $(F T I R)$ spectral image and $(\mathbf{B}) v(=\mathrm{C}-\mathrm{D})$ spectral image to show localisation of $\mathrm{D}_{8}$-AA.

Figure 2 Arachidonic acid (AA) primes the 'soil' for prostate cancer (CaP) invasion. Mesenchymal cells isolated from primary human bone marrow (BM) were grown in the presence of $50 \mu \mathrm{M}$ linoleic acid (LA), arachidonic acid (AA), $\alpha$-linolenic acid (ALA), eicosapentaenoic acid (EPA) or oleic acid in basal media supplemented with $5 \times 10^{-7} \mathrm{M}$ hydrocortisone to induce adipocyte differentiation. Control cultures include differentiation in proprietary adipogenic media and long-term bone marrow stroma (BMS) growth media. (A) Phase contrast photo-micrographic mosaics comprising II $\times 8$ overlapping fields of view merged using the Mosaic I plug-in (Image]). Adipocytes are distinguished from dark stromal background as phase-bright cells. Scale bar $=1 \mathrm{~mm}$. (B) Histogram showing number of adipocytes formed in the presence of each lipid $(n=3)$. (C) Histogram showing the invasive stimulus of specific lipid-laden adipocytes derived from human BM mesenchymal stem cells (MSC) with $5 \times 10^{-7} \mathrm{M}$ hydrocortisone. $2 \times 10^{5} \mathrm{PC}-3$-GFP cells were seeded in modified Boyden chambers and invasion was measured after I $8 \mathrm{~h}$ using a bottom reading BMG FLUOstar OPTIMA plate reader at 488/520 nm (excitation/emission filter). 
A
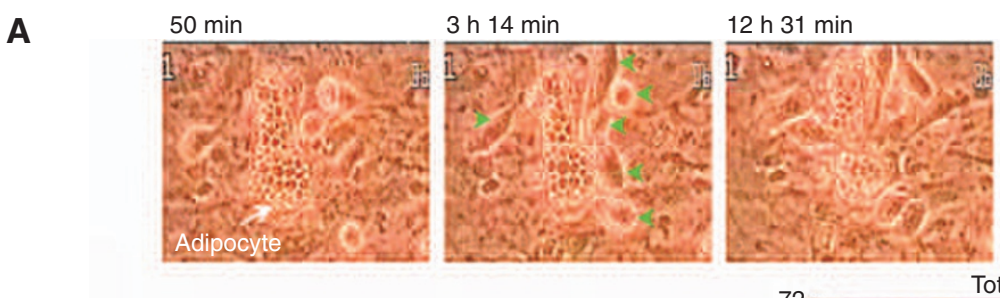

$43 \mathrm{~h} 17 \mathrm{~min}$
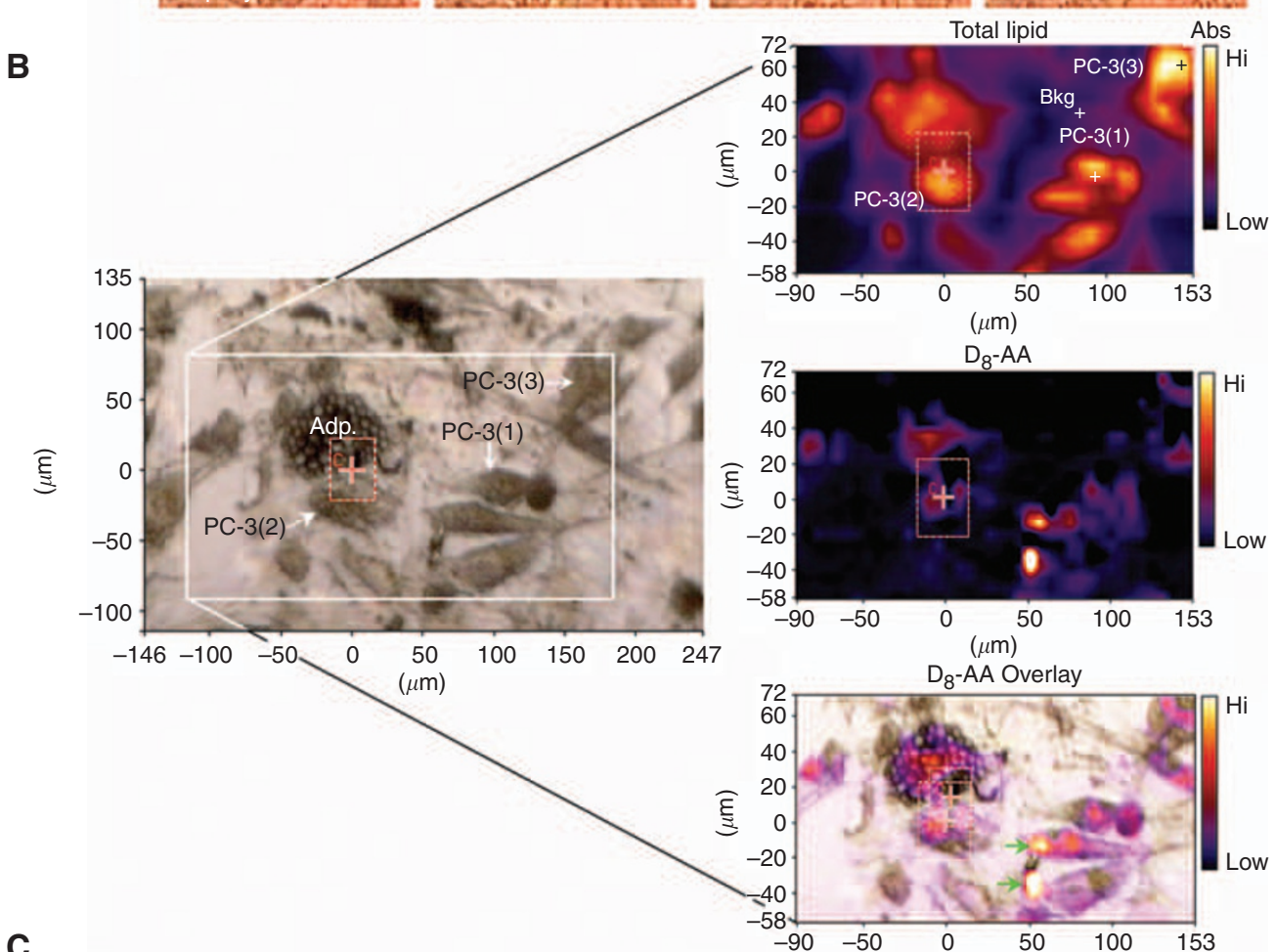

C
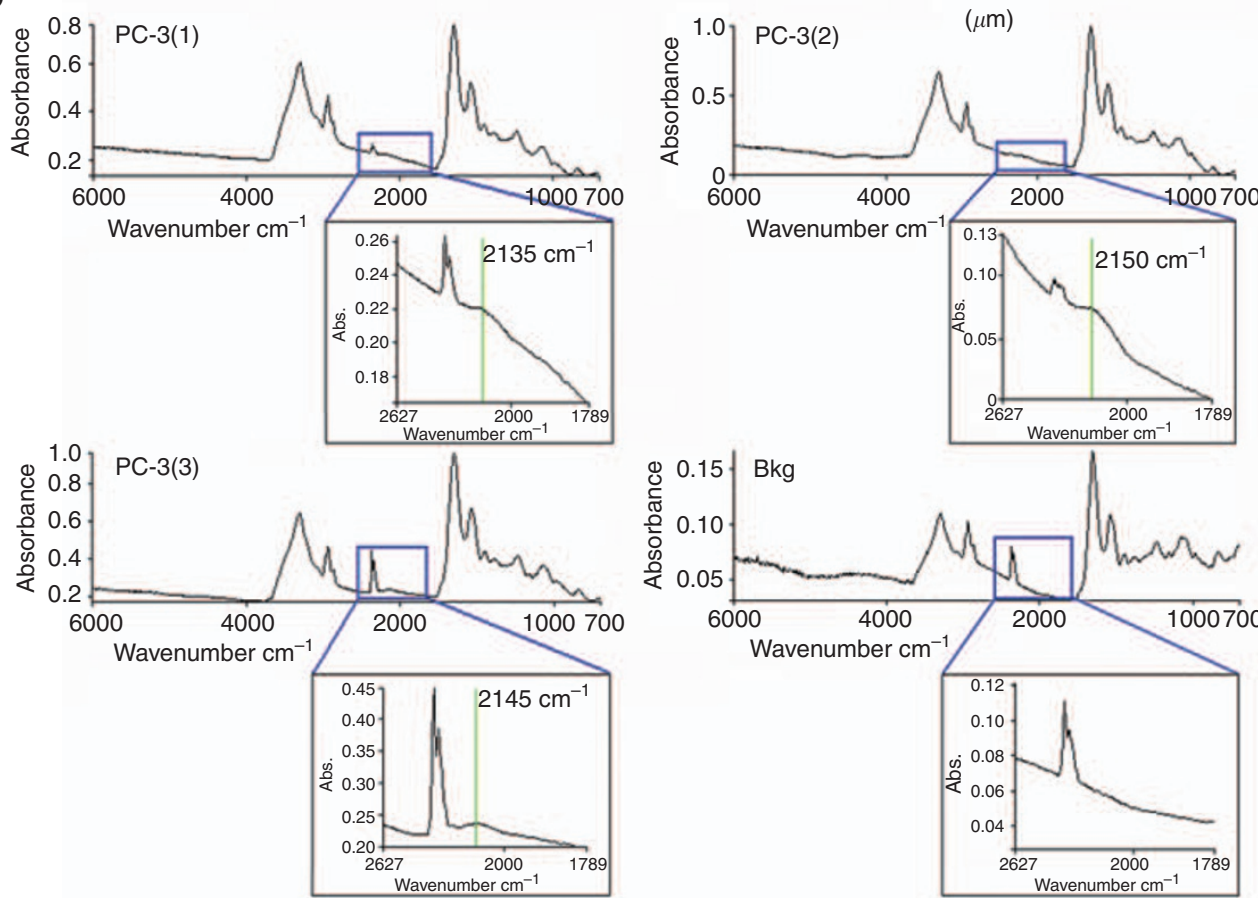

Figure 4 PC-3 cells target and take-up arachidonic acid (AA) from AA-loaded human bone marrow adipocyte (BM-Ad). (A) Interaction of PC-3 cells cocultured with AA-pulsed adipocytes from human BM mesenchymal cells followed by time-lapse video-microscopy. Adipocyte= white arrow, PC-3 cells = green arrows. (B) Photomicrographs showing separate phase contrast, total lipid and D8-AA Fourier Transform Infrared spectroscopy (FTIR) spectral image and a phase contrast $\mathrm{D}_{8}$-AA overlaid image of a PC-3 $\mathrm{D}_{8}$-AA loaded BM adipocyte (Adp) co-culture. (C) Fourier Transform Infrared Spectroscopy spectra of four regions defined in the phase contrast and total lipid spectra photomicrograph shown in B, with inset high-resolution spectra of the $1789-2627 \mathrm{~cm}^{-1}$ region corresponding to $\mathrm{D}_{8}-\mathrm{AA}$. Bkg= background. 


\section{Uptake of $\mathrm{D}_{\mathbf{8}}$-AA from BM-Ad}

Time-lapse video-microscopy data shows $\mathrm{CaP}$ cells interact with adipocytes resulting in loss of lipids from the adipocytes. However, time-lapse does not provide information on mechanisms of AA uptake within this environment. Lipid could be taken up by direct interaction between adipocytes and $\mathrm{CaP}$ cells or by assimilation from the surrounding media once AA is released by adipocytes following cellular interaction or after the rupture of lipid micelles during the destructive process. AA uptake can be followed by timelapse microscopy and FACS using Nile Red staining (Brown et al, 2006). However, this approach does not distinguish whether AA comes directly from adipocytes, from free AA, or from AA derived from other lipid sources. Utilising $\mathrm{D}_{8}$-AA and FTIR spectroscopy, the transit of AA from adipocytes to the $\mathrm{CaP}$ cells can be traced (Figure 4).

Figure 4B shows an optical photomicrograph of PC-3 cells below and to the right of an adipocyte. FTIR molecular images obtained from the boxed area and processed to display intensity distribution of the total lipid hydrocarbon and $v(C-D)$ signals, indicate the location of $\mathrm{D}_{8}-\mathrm{AA}$ and/or its deuterated metabolites. The final panel overlays the $\mathrm{v}(\mathrm{C}-\mathrm{D})$ signal on the optical photomicrograph of the region providing spatial localisation of the $\mathrm{D}_{8}-\mathrm{AA}$. This enables viewing of each cell within the imaging field and acquisition of spectra from site-specific locations, CaP cells and the surrounding stromal matrix to determine $\mathrm{D}_{8}-\mathrm{AA}$ uptake. The total lipid spectra provide the molecular location of each cell within the field of chemical analysis. Analysis of $\mathrm{D}_{8}-\mathrm{AA}$, shown by the $\mathrm{v}(\mathrm{C}-\mathrm{D})$ signal around $2150 \mathrm{~cm}^{-1}$, shows that $\mathrm{D}_{8}$-AA is located at high levels within the adipocyte and in $\mathrm{CaP}$ cells. Background spectra were obtained from the location denoted 'Bkg', which show that the peak within the $v(C-D)$ spectral range is absent, showing that the $D_{8}-A A$ and/or its metabolites are contained within the cellular fraction, specifically within adipocytes and $\mathrm{CaP}$ cells, but not within stromal cells.

Intra-cellular localisation of $\mathrm{D}_{8}$-AA and/or its metabolites was determined using greater magnification of the infrared spectral image. Figure 5 shows an optical photomicrograph of a PC-3 cell flanked by $D_{8}$-AA loaded mBM-Ad. $v(C-D)$ spectral maps show that $\mathrm{D}_{8}$-AA localises around the $\mathrm{PC}-3$ nucleus, unlike the total lipid-hydrocarbon signal, which is more homogenous throughout the PC-3 cell.

\section{Temporal effects of $\mathrm{D}_{8}$-AA exposure to endogenous biomolecules in PC-3 cells}

The intra-cellular location of AA following uptake by $\mathrm{CaP}$ cells (Brown et al, 2006; Gazi et al, 2009) suggests that AA is being used for specific purposes within the cell. Utilising $D_{8}$-AA and FTIR, it is possible to follow spectral changes in the cell's biochemical constituents over time and relate this information to the $\mathrm{D}_{8}$-AA signal.

PC-3 cells in control and $100 \mu \mathrm{M} \mathrm{D}_{8}$-AA conditioned media (Figure 6A) demonstrate an initial rise $(0-60 \mathrm{~min} ; P=>0.05)$ in endogenous lipid signal followed by a significant fall. This coincides with an increase in phosphate signal within $\mathrm{D}_{8}-\mathrm{AA}$ exposed $\mathrm{CaP}$ cells. A much smaller rise in endogenous lipid signal was observed with $25 \mu \mathrm{M} \mathrm{D}_{8}$-AA at earlier time points. The phosphate intensity for $25 \mu \mathrm{M} \mathrm{D}_{8}$-AA exposed cells did not show significant differences between phosphate intensities at 0 and 90 min $(P=0.35)$, but thereafter a rise in mean $v(=C-D)$ signal was seen, with a significant difference in phosphate signal between 90 and 180 mins $(P=0.05)$. This coincided with the decreased mean $v(=C-D)$ signal observed in the time-course $D_{8}$-AA uptake (Supplementary Figure 2).

\section{DISCUSSION}

The role of lipids in the development and progression of $\mathrm{CaP}$ is controversial. The microscopic prevalence of $\mathrm{CaP}$ is widespread
(Franks, 1954), but the incidence of clinically relevant disease varies internationally, being highest in developed western countries (Ferlay et al, 2004). These populations have large numbers of clinically obese men (WHO, 2006) and their general diet is enriched with foods containing high levels of fat. However, the relationship between obesity and incidence of $\mathrm{CaP}$ is uncertain (Renehan et al, 2008).

Lanier et al, 1996 and Rose, 1997 followed changes in Inuit and Japanese population diets, showing that both populations coincidentally experienced increases in clinically significant $\mathrm{CaP}$, as their diet changed from a fish-based diet rich in long chain $\omega-3$ lipids (EPA/DHA) to an $\omega-6$ enriched westernised diet. It is hypothesized that changes in $\omega-6: \omega-3$ ratio has led to increased incidence of clinically significant prostate, breast, pancreatic, and colon cancers. This observation mirrors changes in $\omega-6: \omega-3$ ratio before and after the industrial revolution in 'western' countries. Historically, 'western' diets had lower saturated and unsaturated fat levels, with $\omega-6: \omega-3$ ratios of about $1: 1$. The augmented use of modern vegetable oils has increased western $\omega$-6 PUFA consumption at the expense of $\omega-3$ PUFA (Kris-Etherton et al, 2000). During this period the presentation of clinically significant $\mathrm{CaP}$ has increased (Hsing et al, 2000). Although there are a number of potential reasons for this, such as increased longevity and better $\mathrm{CaP}$ detection/diagnosis, it is interesting to hypothesise that the increase is directly related to dietary changes.

As epidemiological evidence suggests that the switch to modern vegetable oils has upset the differential balance of $\omega-6: \omega-3$ PUFAs resulting in increased risk of developing clinically aggressive $\mathrm{CaP}$, we studied the role of PUFAs in CaP metastatic behaviour utilising validated in vitro models (Hart et al, 2005), supplemented by timelapse video-microscopy and functional interrogation using FTIRbased spectroscopy. Oils commonly featured in western diets were made up at concentrations similar to the dose of AA previously shown to induce maximal invasion (Brown et al, 2006) and within the concentration range reported by Maurin et al 2002 as having an effect on human osteoblasts. Using these oils we were unable to induce $\mathrm{CaP}$ cellular invasion in our experiments. This is unlikely to be due to the cyclodextrin used to encage lipid droplets, (required for emulsification of the oil for in vitro experimentation) as AA control was similarly prepared. This attracted $\mathrm{CaP}$ avidly as reported herein and elsewhere (Brown et al, 2006). This finding shows that dietary oils in unprocessed forms are not the factor inducing the observed cellular changes presented herein.

Linoleic acid and ALA both promote proliferation and migration of PC-3 cells, therefore we assessed each lipid component separately as a cyclodextrin-induced emulsion to determine their stimulatory effects. Both induced CaP invasion, with $30 \mu \mathrm{g} \mathrm{ml}^{-1} \mathrm{LA}$ inducing the greatest level. The reduced invasion towards LA compared with AA may be because of the cells' requirement to convert LA into AA and to metabolize AA to induce invasion. It has been postulated (Angelucci et al, 2008) that proliferation and migration is controlled by an autocrine loop maintaining EGFR signalling which, in turn, is controlled by AA-induced TGF- $\alpha$. This suggests for LA to stimulate invasion, it must be first metabolised to AA, which is then metabolised by 5 -LOX and COX-2 to induce EGFR-mediated signalling of invasion. This may be less efficient at stimulating invasion than supplying AA directly.

$\alpha$-Linolenic acid, a short chain $\omega-3$ PUFA (C18) from plant oils, induced high levels of invasion, this was not as pronounced with LA but it occurred maximally at lower concentrations, unlike the long chain $\omega-3$ PUFAs, EPA (C20), and DHA (C22), which reduce $\mathrm{CaP}$ migration towards BMS (Brown et al, 2006). This supports evidence showing that ALA increases the risk of $\mathrm{CaP}$ progression (Leitzmann et al, 2004).

Invasion towards $\omega$-9 oleic acid, the main component of olive oil, was also seen. This conflicts with perceived thinking about olive oil, previously thought to be a major dietary component responsible for reducing the risk of clinically significant $\mathrm{CaP}$ in 
A

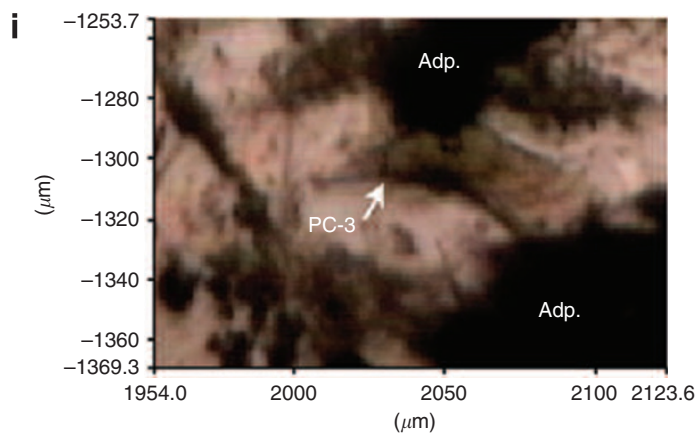

ii
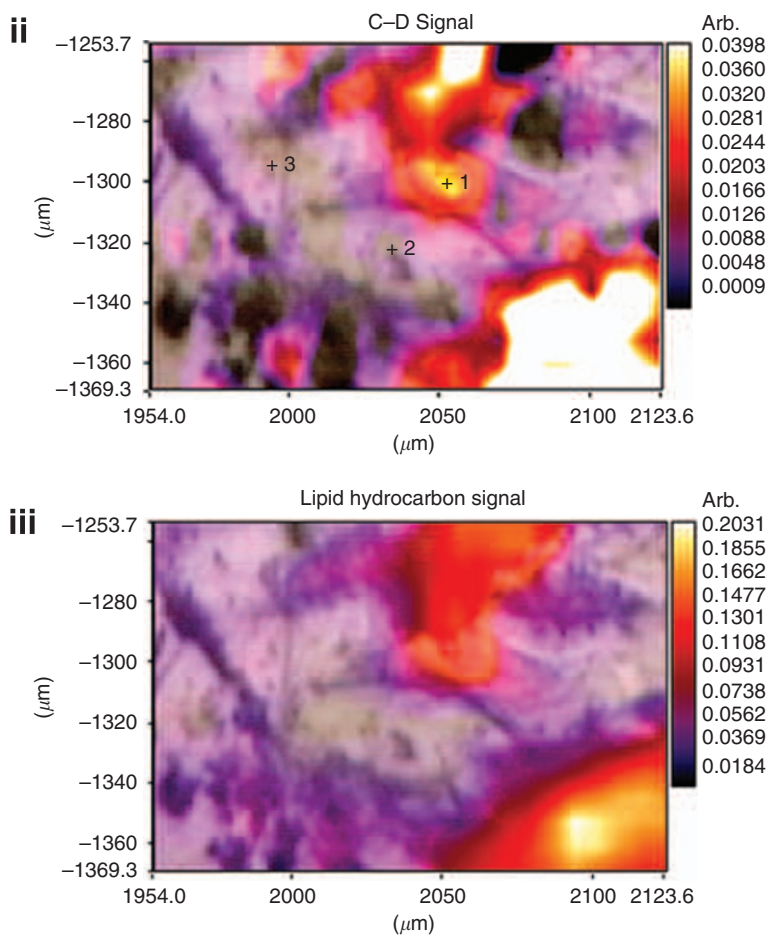

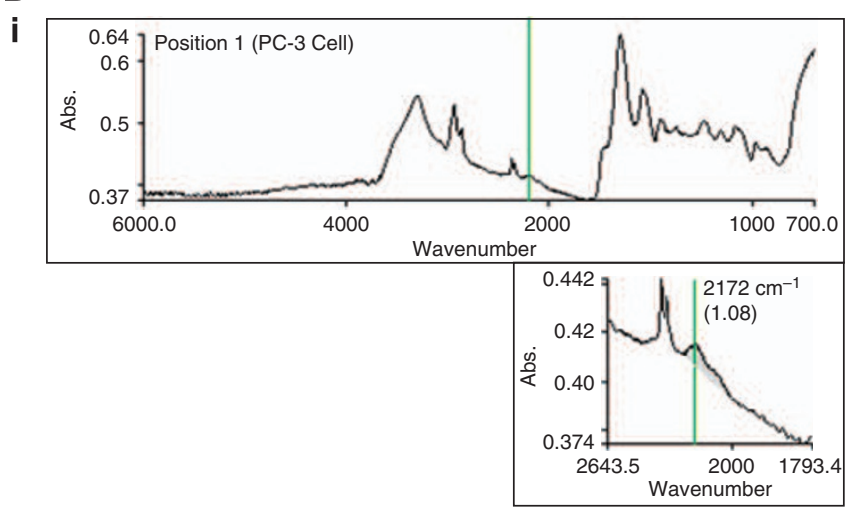

ii
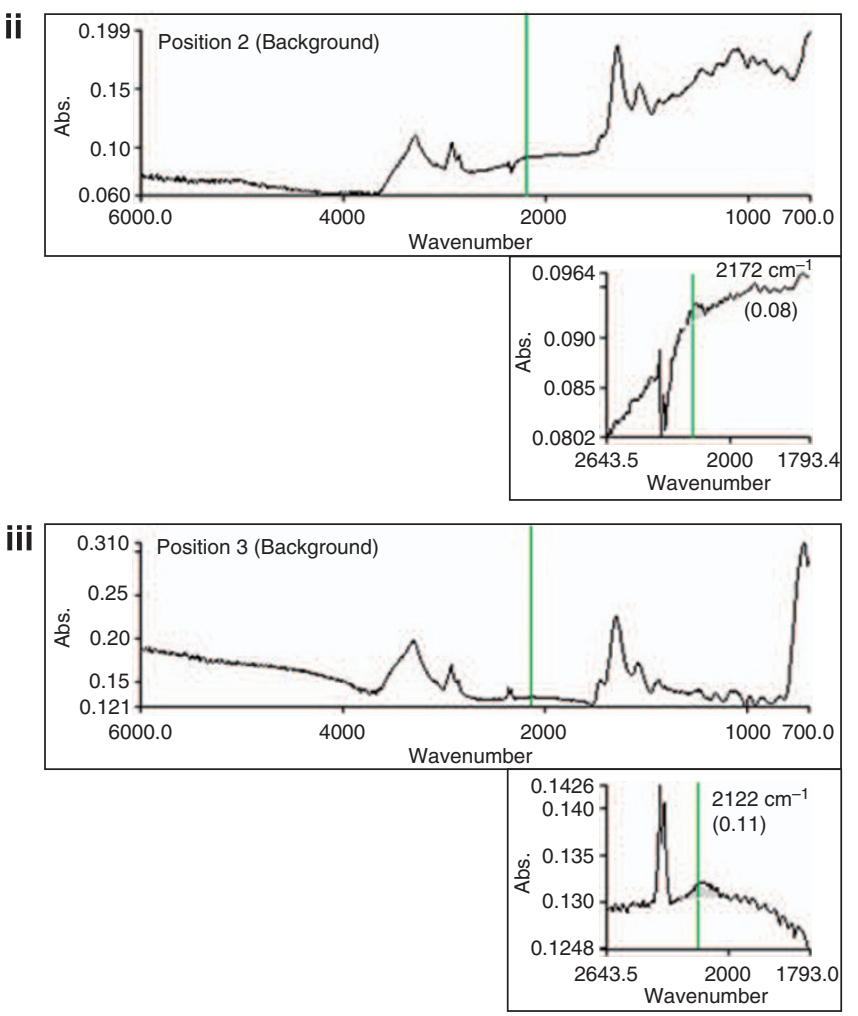

Figure 5 Arachidonic acid (AA) localises around the nucleus following uptake by PC-3 cells. (Ai) Phase contrast image of a PC-3/bone marrow adipocyte (BM-Ad) co-culture showing a PC-3 cell flanked top and bottom by D $\mathrm{D}_{8}$-AA loaded adipocytes; (Aii) Fourier Transform Infrared spectroscopy (FTIR)spectral micrograph of the $v(C-D)$ signal overlaid on to the optical photomicrograph, with increasing signal absorbance depicted by a shift towards red/ white colours; (Aiii) FTIR-spectral micrograph of the total lipid hydrocarbon signal overlaid onto the optical photomicrograph with increasing signal absorbance depicted by a shift towards red/white colours. (B) Fourier Transform Infrared spectroscopy-spectral signatures from i) PC-3 cell, (ii + iii) background as defined in Figure 6Ai and Aii. Fourier Transform Infrared spectroscopy Spectral profiles (inset) concentrate on the 1793.4-2643.5 $\mathrm{cm}^{-1}$ region encompassing the $(\mathbf{C}, \mathbf{D})$ spectral region (highlighted by the green vertical line).

Mediterranean men (Simopoulos, 2004; Stamatiou et al, 2007). Oleic acid has been shown to activate EGFR signalling in both endothelial (Vacaresse et al, 1999) and breast cancer cell lines (Soto-Guzman et al, 2008). Angelucci et al (2008) has previously reported that AA stimulates the EGFR pathway leading to increased cellular invasion. This suggests that within our in vitro model, where oleic acid is the predominant lipid within the system, oleic acid may act in a similar way to AA and induces invasion via the EGFR signalling pathway.

Differences between dietary oils and their individual constituents in inducing invasion may be because of lipid mixture they contain. We have shown previously that $5 \mu \mathrm{M}$ EPA or DHA inhibits the invasive effects of $10 \mu \mathrm{m} \mathrm{AA}$ on CaP. It is possible that the ratio of $\omega-6: \omega-3$ PUFAs in oils tested was within the range which nullified the stimulatory signal of $\omega-6$. Other lipids within the mixture may have masked the effect of individual PUFAs. Another possible factor is the form in which prostate cells encounter lipid. Lipids are insoluble and are stored in adipocytes within target tissues. It may be that $\mathrm{CaP}$ cells presented directly with neat dietary oils are unable to utilise this substrate. Once the oil mixture has been taken up and 'processed' by adipocytes, resulting in production and storage of $\mathrm{AA}$ and its metabolites $\mathrm{PGE}_{2}$ and 5-HETE, CaP cells may utilise specific lipid or metabolites to induce invasion. If this notion was true, the BM-Ad may be of considerable importance in initiating metastatic implantation. Adipocytes are present in all tissues, but $\mathrm{CaP}$ metastasis to subcutaneous tissue is unusual, whereas spread to BM is very common. This raises the question of whether adipocytes in all 

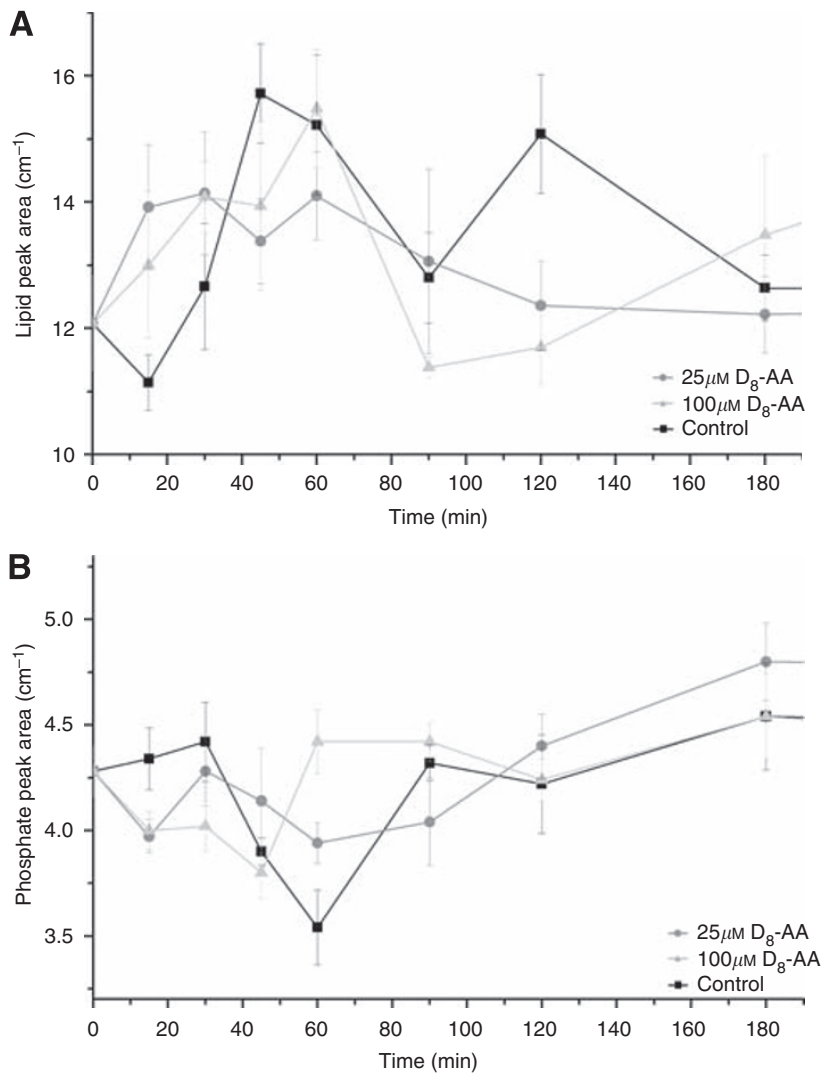

Figure 6 Chemometric analysis of arachidonic acid (AA) metabolism in PC-3 cells. Endogenous (A) lipid and (B) phosphorylation signals in PC-3 cells following exposure to $25 \mu \mathrm{M}$ and $100 \mu \mathrm{M}$ D8-AA or no $D_{8}-A A$ (control). Fourier Transform Infrared spectroscopy (FTIR) measurements over $3 \mathrm{~h}$.

areas function similarly. Adipocytes in different areas may process/store fat differently according to the role that they are supporting and although few studies have been conducted in this area, it has been reported that BM-Ad's have distinct and critical differences compared with extramedullary adipocytes (Bathija et al, 1979; Tavassoli, 1984; Gimble et al, 1992).

Although the exact function of BM-Ads is unclear (Nuttall et al, 1998) they are numerous in this location, where they have a key role in haematopoiesis (Gimble et al, 1992), with cobblestone areas close to adipocytes representing active haematopoiesis. Furthermore, propagation of long term BM culture fails when adipocytes are absent, following arrest of differentiation from adipocyte precursors in steroid-free culture (Brown et al, 2006). Therefore, as BM-Ads are integrally involved in haematopoietic cell proliferation/propagation, they may also be an important component in $\mathrm{CaP}-\mathrm{BMS}$ interaction. This may explain the co-localisation of $\mathrm{CaP}$ cells with adipocytes and the consequent influence on $\mathrm{CaP}$ migration and growth in vitro (Tokuda et al, 2003; Brown et al, 2006; Gazi et al, 2007).

Following these observations, we studied the metabolites and/or AA stored within BM-Ad and their surrounding microenvironment utilising an adipocyte differentiation culture system. This protocol amplifies isolated primary human BM-MSC in culture using basal stem cell media (BSCM) with adipogenic stimulatory supplements to induce differentiation down the adipocyte pathway. Although this method gave rise to BMS containing adipocytes, their number was considerably lower than that achieved with established methods using human BM aspirates in long-term culture (Coutinho et al, 1993). This may be because of human aspirates already containing greater numbers of adipocyte precursors (unlike MSC systems, where adipocyte precursors must undergo adipogenic differentiation) and/or to the long-term BM culture media containing selected FCS and horse serum, which support adipogenesis/haematopoiesis. To assess the effect of specific PUFAs on BM-MSC adipogenesis, we utilised BSCM supplemented with hydrocortisone (an essential factor for inducing adipogenesis within BMS cultures), which we have shown previously to be capable of deriving BM-Ad containing specific fatty acids (Gazi et al, 2007). We now show for the first time that specific lipids have differential effects on adipocyte differentiation in human BMS. Linoleic acid, ALA, EPA, and oleic acid induced differentiation of similar numbers of adipocytes as the proprietary adipogenic supplements but at the same concentration, AA induced four-fold greater adipogenesis than proprietary media. This suggests that AA interacts with adipogenic differentiation pathways, inducing a proportional increase in adipocyte numbers. Thus, in the presence of specific lipids, the number of BM-Ad will increase, potentially augmenting the chemoattractive stimulus of migrating cancer cells known to be in circulation in escalating numbers as cancer load increases (Danila et al, 2007) and increasing the statistical chance of 'proximity' encounters between migrating cancer cells and BM-Ad. Thus, in a 'Darwinian' sense, the 'fitness' of the cancer cell to survive and propagate in red BM is enhanced. Specific PUFAs also had differential effects on cancer cell migration (Figure 2C). There was significant induction by all PUFAs but the AA-loaded adipocytes were especially potent stimulators, surpassing that induced by free AA control. Thus, AA not only induces greater adipogenesis than other PUFAs, it's processing by the adipocyte also leads to super-added chemoattractive stimulation. This may be because of the production of metabolites and initiation of additional pathways that are themselves potent stimulators of invasion (Hassan and Carraway, 2006; Angelucci et al, 2008).

The strong stimulation of invasion by EPA-loaded adipocytes is paradoxical, running counter to previous data (Brown et al, 2006) showing that marine $\omega$-3 PUFAs inhibit $\mathrm{CaP}$ invasion. The result herein may be because of adipocytes being loaded with EPA in relative isolation to other lipids. Bagga et al (2003) showed that the COX-2 metabolite of EPA, PGE3, although not mitogenic itself, could regulate COX-2 expression and induce IL-6 secretion from macrophages. Although similar in action and signalling to $\mathrm{PGE}_{2}$, $\mathrm{PGE}_{3}$ is not as efficient in inducing COX-2 gene expression. In our system, where EPA is the main lipid within adipocytes, EPA may be metabolized by the high expression of COX-2, generating $\mathrm{PGE}_{3}$ and stimulating IL- 6 production. Increased serum IL-6 levels are associated with poorer prognosis in $\mathrm{CaP}$ (Nakashima et al, 2000) and are known to have proliferative properties which induce cancer-like behaviour, including migration of gastric cancer cells (Lin et al, 2007), trans-endothelial migration of melanoma (Kitamura et al, 1997) and ovarian cell lines NOMI and SKOV (Obata et al, 1997).

We showed previously that $\mathrm{CaP}$ cells frequently associate with BM-Ads in co-culture, resulting in the appearance of cytoplasmic lipid vesicles. This observation was supported by Tokuda et al (2003), who showed direct interactions of $\mathrm{CaP}$ cells with epididymal adipocytes, with concomitant uptake of lipid droplets by $\mathrm{CaP}$ cells. Time-linked measurements of co-cultures provide a unique insight to the interaction between $\mathrm{CaP}$ cells and BM-Ads. Over $44 \mathrm{~h}, \mathrm{PC}-3$ cells migrated towards, made contact with, and induced wholesale destruction of adipocytes (Figure $4 \mathrm{~A}$ and Supplementary video). When contact was established between epithelial cell and adipocyte, there was a marked induction of cellular activity with dramatic and visible prostate cellular recruitment and proliferation, with concomitant changes in morphology and motility. This suggests that BM-Ads are the focal point for malignant epithelial-cell aggregation and proliferation within BMS and that cellular behaviour can be altered dramatically following lipid BM-Ad contact and lipid uptake. Circulating PECs can be detected in BMS of CaP patients even in early stage disease 
(Ross et al, 2005), but few cells survive to form a metastasis (Melchior et al, 1997). Our data suggests that direct interactions of such cells with BM-Ad will enhance their capacity to survive and propagate.

Using FTIR to track deuterated AA in loaded adipocytes, the $\mathrm{D}_{8^{-}}$ AA signal could only be detected in CaP cells associated with those adipocytes and in remnants of the adipocytes themselves, thus suggesting a specific mechanism of uptake and utilisation of AA by $\mathrm{CaP}$ cells. This process was not apparent in stromal cells and is clearly not a process of passive diffusion from the surrounding microenvironment as that the deuterated signal, v(C-D), could not be detected within the surrounding micro-environment. Objective measurement of direct $\mathrm{D}_{8}$-AA uptake by $\mathrm{CaP}$ cells from adipocytes supports observations using electron and confocal microscopy (Tokuda et al, 2003; Brown et al, 2006; Gazi et al, 2007) showing direct interaction of $\mathrm{CaP}$ cells with adipocytes with direct acquisition of lipid droplets. High-resolution FTIR mapping of lipid laden $\mathrm{CaP}$ cells (Figure 5) shows that $\mathrm{v}(\mathrm{C}-\mathrm{D})$ localises around the $\mathrm{CaP}$ nucleus. Apparent nuclear localisation may occur at the thickest region of the cell, with greater amounts of $\mathrm{D}_{8}-\mathrm{AA}$ (or metabolite) for detection. However, the intensity of lipid hydrocarbon signal across each $\mathrm{CaP}$ cell is homogenous, indicating a non-significant change in path-length across these cells. The observed phenomenon is, therefore, likely because of translocation of lipid from the cell membrane towards the nucleus, a process previously observed using Nile Red (Brown et al, 2006). This migration of captured lipids may be a conserved mechanism, as measurements using synchroton radiation SR-FTIR of $\mathrm{CaP}$ cells co-incubated with $\mathrm{D}_{31}$-PA loaded adipocytes also showed FA location to the nuclear region (Gazi et al, 2009). The reason for this localisation is unknown and future studies are required to determine which organelles the lipids are localising to.

Fourier Transform Infrared spectroscopy analysis enables the generation of chemical maps of cells, with spectral peaks indicating the presence and relative quantities of specific chemical moieties. Combining this with time-lapse microscopy allows temporal analysis of defined chemical groups, providing the investigator with dynamic metabolic data. These techniques used herein with $\mathrm{D}_{8}$-AA showed an initial increase in endogenous lipid signal in $\mathrm{CaP}$ cells followed by a drop after $60 \mathrm{~min}$. This drop coincided with an increase in the phosphate signal (Figure 6). Various factors may be contributory, levels of unesterified cytosolic AA are tightly controlled by two distinct, coordinated pathways, for exposure to low or high AA concentrations (Monjazeb et al, 2006). The predominant 'high-affinity-low-capacity' pathway, incorporates low concentrations of intracellular AA into glycerolipids

\section{REFERENCES}

Allen TD (1987) Time lapse video microscopy using an animation control unit. J Microsc 147: 129-135

Angelucci A, Garofalo S, Speca S, Bovadilla A, Gravina GL, Muzi P, Vicentini C, Bologna M (2008) Arachidonic acid modulates the crosstalk between prostate carcinoma and bone stromal cells. Endocr Relat Cancer 15: $91-100$

Bagga D, Wang L, Farias-Eisner R, Glaspy JA, Reddy ST (2003) Differential effects of prostaglandin derived from omega- 6 and omega- 3 polyunsaturated fatty acids on COX-2 expression and IL-6 secretion. Proc Nat Acad Sci USA 100: $1751-1756$

Bathija A, Davis S, Trubowitz S (1979) Bone marrow adipose tissue: response to acute starvation. Am J Hematol 6: $191-198$

Brown MD, Hart CA, Gazi E, Bagley S, Clarke NW (2006) Promotion of prostatic metastatic migration towards human bone marrow stoma by Omega 6 and its inhibition by Omega 3 PUFAs. $\mathrm{Br} J$ Cancer 94: $842-853$

Coutinho LH, Gilleece MH, de Wynter E, Will A, Testa NG (1993) Clonal and long-term cultures using human bone marrow. In In Haemopoiesis: responsible for phospholipid-arachidonate re-modelling. When the intra-cytoplasmic concentrations of unesterified AA overwhelm this pathway, a 'low-affinity-high-capacity' pathway incorporates unesterified AA primarily into TAG and diarachidonyl phospholipids (Monjazeb et al, 2006). This may also explain the absence of a similar rise in CaP cells incubated with $25 \mu \mathrm{M} \mathrm{D_{8- }}$ $\mathrm{AA}$ as the metabolic demand resulting from media exchange was partially compensated by $\mathrm{D}_{8}-\mathrm{AA}$, which does not contribute to the measured endogenous lipid signal. The influx of $\mathrm{D}_{8}$-AA may also have been at sufficiently low levels for the cell to sequester PUFAs using only the high-affinity-low-capacity pathway.

Prostate cancer cells exposed to $100 \mu \mathrm{M} \mathrm{D} \mathrm{D}_{8}$-AA exhibited significant rises in endogenous lipid signal between $0-60 \mathrm{~min}(P<0.05)$ (Figure 6A). This may be because of phospholipid biosynthesis and/or TAG synthesis to sequester a large $\mathrm{D}_{8}$-AA influx, as part of its regulatory mechanism. The lipid signal for the $100 \mu \mathrm{M} \mathrm{D}$-AA exposed cells fell significantly after 60 mins, suggesting the initiation of TAG breakdown and mobilisation of $\mathrm{D}_{8}$-AA. Between $90-120$ mins, where lipid levels were low in $100 \mu \mathrm{M}$ D8-AA exposed cells, we found a reduction in $v(=\mathrm{C}-\mathrm{D}$ ) signal (Supplementary Figure 2). These data suggest that mobilized AA is subsequently metabolised by the COX/LOX pathway to eicosanoids and exported out of cells. The significant upregulation of phosphate signal at time-points $60 \mathrm{~min}$ (compared with $40 \mathrm{mins}$ ), for the $100 \mu \mathrm{M} \mathrm{D}_{8}$-AA exposed cells (Figure 6B), could result from effects of eicosanoids binding to cell surface receptors and activating kinase pathways for stimulating cell growth/proliferation.

In summary, we have shown that dietary oils in their native form do not stimulate $\mathrm{CaP}$ progression/invasion unlike their pure constituent PUFAs. This suggests that dietary oils must be processed before they becoming stimulants for invasion. AA induces proportionally higher levels of BM-Ad differentiation than other PUFAs and these AA-loaded adipocytes are potent inducers of PEC invasion. Direct monitoring of $\mathrm{CaP}$ cells in BMS co-culture shows that they migrate towards and interact directly with AA-loaded adipocytes. This interaction is followed by direct uptake and metabolism of AA by $\mathrm{CaP}$ cells, resulting in the destruction of adipocyte and transformation of the cancer cell into a more aggressive and motile phenotype. Taken together, the data supports the hypothesis that $\mathrm{AA}$ not only promotes $\mathrm{CaP}$ invasion, it also prepares the BMS 'soil', making it more supportive for implantation and propagation of the migrating metastatic cell.

Supplementary Information accompanies the paper on British Journal of Cancer website (http://www.nature.com/bjc)
A Practical Approach Testa NG (ed) pp. 75 -10. Oxford University Press: Oxford

Crawford ED (2003) Epidemiology of prostate cancer. Urology 62: 3-12

Danila DC, Heller G, Gignac GA, Gonzalez-Espinoza R, Anand A, Tanaka E, Lilja H, Schwartz L, Larson S, Fleisher M, Scher HI (2007) Circulating tumor cell number and prognosis in progressive castration-resistant prostate cancer. Clin Cancer Res 13: $7053-7058$

Dodds RA, Gowen M, Bradbeer JN (1994) Microcytophotometric analysis of human osteoclast metabolism: lack of activity in certain oxidative pathways indicates inability to sustain biosynthesis during resorption. J Histochem Cytochem 42: 599-606

Ferlay J, Bray F, Pisani P, Parkin DM (2004) GLOBOCAN 2002: Cancer Incidence, Mortality and Prevalence Worldwide. IARC Cancer Base No. 5 Version 2.0. Lyon, France: IARCPress

Franks LM (1954) Latent carcinoma of the prostate. J Pathol Bacteriol 68: $603-616$

Gartner S, Kaplan HS (1980) Long-term culture of human bone marrow cells. Proc Natl Acad Sci USA 77: 4756-4759 
Gazi E, Gardner P, Lockyer NP, Hart CA, Brown MD, Clarke NW (2007) Direct evidence of lipid translocation between adipocytes and prostate cancer cells with imaging FTIR microspectroscopy. J Lipid Res 48: $1846-1856$

Gazi E, Harvey TJ, Brown MD, Lockyer NP, Gardner P, Clarke NW (2009) A FTIR microspectroscopic study of the uptake and metabolism of isotopically labelled fatty acids by metastatic prostate cancer. Vib Spectrosc 50(1): 99-105

Ghosh J (2004) Rapid induction of apoptosis in prostate cancer cells by selenium: reversal by metabolites of arachidonate 5-lipoxygenase. Biochem Biophys Res Commun 315: 624-635

Gimble JM, Youkhana K, Hua X, Bass H, Medina K, Sullivan M, Greenberger J, Wang CS (1992) Adipogenesis in a myeloid supporting bone marrow stromal cell line. J Cell Biochem 50: 73-82

Hart CA, Brown M, Bagley S, Sharrard M, Clarke NW (2005) Invasive characteristics of human prostatic epithelial cells: understanding the metastatic process. $\mathrm{Br} J$ Cancer 92: $503-512$

Hassan S, Carraway RE (2006) Involvement of arachidonic acid metabolism and EGF receptor in neurotensin-induced prostate cancer PC3 cell growth. Regul Pept 133: 105-114

Honn KV, Tang DG, Gao X, Butovich IA, Liu B, Timar J, Hagmann W (1994) 12-lipoxygenases and 12(S)-HETE: role in cancer metastasis. Cancer Metastasis Rev 13: $365-396$

Hsing AW, Tsao L, Devesa SS (2000) International trends and patterns of prostate cancer incidence and mortality. Int J Cancer 85: 60-67

Hughes-Fulford M, Li CF, Boonyaratanakornkit J, Sayyah S (2006) Arachidonic acid activates phosphatidylinositol 3-kinase signaling and induces gene expression in prostate cancer. Cancer Res 66: 1427-1433

Kitamura Y, Morita I, Nihei Z, Mishima Y, Murota S (1997) Effect of IL-6 on tumor cell invasion of vascular endothelial monolayers. Surg Today 27: $534-541$

Kris-Etherton PM, Taylor DS, Yu-Poth S, Huth P, Moriarty K, Fishell V, Hargrove RL, Zhao G, Etherton TD (2000) Polyunsaturated fatty acids in the food chain in the United States. Am J Clin Nutr 71: 179S-188S

Lanier AP, Kelly JJ, Smith B, Harpster AP, Tanttila H, Amadon C, Beckworth D, Key C, Davidson AM (1996) Alaska native cancer update: incidence rates 1989-1993. Cancer Epidemiol Biomarkers Prev 5: $749-751$

Leitzmann MF, Stampfer MJ, Michaud DS, Augustsson K, Colditz GC, Willett WC, Giovannucci EL (2004) Dietary intake of n-3 and n-6 fatty acids and the risk of prostate cancer. Am J Clin Nutr 80: 204-216

Lin MT, Lin BR, Chang CC, Chu CY, Su HJ, Chen ST, Jeng YM, Kuo ML (2007) IL-6 induces AGS gastric cancer cell invasion via activation of the c-Src/RhoA/ROCK signaling pathway. Int J Cancer 120: $2600-2608$

Madsen L, Petersen RK, Kristiansen K (2005) Regulation of adipocyte differentiation and function by polyunsaturated fatty acids. Biochim Biophys Acta 1740: 266-286

Maurin AC, Chavassieux PM, Vericel E, Meunier PJ (2002) Role of polyunsaturated fatty acids in the inhibitory effect of human adipocytes on osteobalstic proliferation. Bone 31(1): 260-266

Melchior SW, Corey E, Ellis WJ, Ross AA, Layton TJ, Oswin MM, Lange PH, Vessella RL (1997) Early tumor cell dissemination in patients with clinically localized carcinoma of the prostate. Clin Cancer Res 3: 249-256
Monjazeb AM, High KP, Connoy A, Hart LS, Koumenis C, Chilton FH (2006) Arachidonic acid-induced gene expression in colon cancer cells. Carcinogenesis 27: $1950-1960$

Nakashima J, Tachibana M, Horiguchi Y, Oya M, Ohigashi T, Asakura H, Murai M (2000) Serum interleukin 6 as a prognostic factor in patients with prostate cancer. Clin Cancer Res 6: 2702-2706

Nie D, Hillman GG, Geddes T, Tang K, Pierson C, Grignon DJ, Honn KV (1998) Platelet-type 12-lipoxygenase in a human prostate carcinoma stimulates angiogenesis and tumor growth. Cancer Res 58: 4047-4051

Norrish AE, Skeaff CM, Arribas GL, Sharpe SJ, Jackson RT (1999) Prostate cancer risk and consumption of fish oils: a dietary biomarker-based casecontrol study. $\mathrm{Br}$ J Cancer 81: $1238-1242$

Nuttall ME, Patton AJ, Olivera DL, Nadeau DP, Gowen M (1998) Human trabecular bone cells are able to express both osteoblastic and adipocytic phenotype: implications for osteopenic disorders. J Bone Miner Res 13: $371-382$

Obata NH, Tamakoshi K, Shibata K, Kikkawa F, Tomoda Y (1997) Effects of interleukin- 6 on in vitro cell attachment, migration and invasion of human ovarian carcinoma. Anticancer Res 17: 337-342

Renehan AG, Tyson M, Egger M, Heller RF, Zwahlen M (2008) Body-mass index and incidence of cancer: a systematic review and meta-analysis of prospective observational studies. Lancet 371: 569-578

Rose DP (1997) Dietary fatty acids and cancer. Am J Clin Nutr 66: 998S - 1003S

Ross DG, Hart CA, McIntyre IG, Ramani VACR, Brown MD, Clarke NW (2005) Multi-marker quantitative RT-PCR based analysis of blood and bone marrow in prostate cancer patients. In Multidisciplinary Prostate Cancer Symposium. American Society of Clinical Oncology: Orlando, Florida, USA

Simopoulos AP (2004) The traditional diet of Greece and cancer. Eur J Cancer Prev 13: $219-230$

Soto-Guzman A, Robledo T, Lopez-Perez M, Salazar EP (2008) Oleic acid induces ERK1/2 activation and AP-1 DNA binding activity through a mechanism involving Src kinase and EGFR transactivation in breast cancer cells. Mol Cell Endocrinol 294: 81 -91

Stamatiou K, Delakas D, Sofras F (2007) Mediterranean diet, monounsaturated: saturated fat ratio and low prostate cancer risk. A myth or a reality? Minerva Urol Nefrol 59: 59-66

Sugano M, Hirahara F (2000) Polyunsaturated fatty acids in the food chain in Japan. Am J Clin Nutr 71: 189S-196S

Tavassoli M (1984) Marrow adipose cells and hemopoiesis: an interpretative review. Exp Hematol 12: 139-146

Tokuda Y, Satoh Y, Fujiyama C, Toda S, Sugihara H, Masaki Z (2003) Prostate cancer cell growth is modulated by adipocyte-cancer cell interaction. BJU Int 91: 716-720

Vacaresse N, Lajoie-Mazenc I, Auge N, Suc I, Frisach MF, Salvayre R, Negre-Salvayre A (1999) Activation of epithelial growth factor receptor pathway by unsaturated fatty acids. Circ Res 85: $892-899$

WHO (2006) Global Database on Body Mass Index. World Health Organisation) WHO. (http://apps.who.int/bmi/index.jsp)

Wynder EL, Rose DP, Cohen LA (1994) Nutrition and prostate cancer: a proposal for dietary intervention. Nutr Cancer 22: 1-10 